\title{
Study of effects of combined spinal epidural analgesia on the course of labour and feto maternal outcome in comparison with the parturients receiving no analgesia
}

\author{
Shoba Bembalgi ${ }^{1}$, Basavaraj Kallapur ${ }^{2}$, Prasad S. ${ }^{3}$, Shruthi M. ${ }^{1 *}$, Amit S. Amble ${ }^{2}$
}

\author{
${ }^{1}$ Department of Obstetrics and Gynecology, ${ }^{2}$ Department of Anaesthesia, Karnataka Institute of Medical Sciences, \\ Hubli, Karnataka, India \\ ${ }^{3}$ Department of Community Medicine, Government Thiruvarur Medical College, Thiruvarur, Tamil Nadu, India
}

Received: 17 July 2018

Accepted: 01 September 2018

\section{*Correspondence:}

Dr. Shruthi M.,

E-mail: shrutigyn@yahoo.com

Copyright: (c) the author(s), publisher and licensee Medip Academy. This is an open-access article distributed under the terms of the Creative Commons Attribution Non-Commercial License, which permits unrestricted non-commercial use, distribution, and reproduction in any medium, provided the original work is properly cited.

\section{ABSTRACT}

Background: The study was aimed to evaluate the effects of combined spinal epidural analgesia on the duration and outcome of labour in nulliparous parturients in comparison with parturients not receiving any analgesia.

Methods: It is a prospective clinical study. The present study was carried out in the labour ward, KIMS Hubli. Nulliparous parturients in early active labour were divided into two groups. CSE group $(\mathrm{n}=40)$ and non CSE group. In present study CSE was performed with intrathecal $1.25 \mathrm{mg}$ of levobupivacaine with $25 \mathrm{mcg}$ fentanyl initially and this was followed by epidural boluses of $10 \mathrm{ml}$ of $0.0625 \%$ Levobupivacaine with $2 \mathrm{mcg} / \mathrm{ml}$ fentanyl through the epidural catheter whenever the patients' pain score is more than 4.

Results: Mean duration of active labour was 139+/-41.2min in CSE group and 251.1+/-57.9 min in non CSE group. The rate of cervical dilatation was $2.63+/-0.66 \mathrm{~cm} / \mathrm{hr}$. in CSE group as compared to $1.45+/-0.38 \mathrm{~cm} / \mathrm{hr}$ in non CSE group. The duration of second stage of labour was similar in both groups. The spontaneous vaginal deliveries was $77.5 \%$ in CSE group as compared to $79.5 \%$ in non CSE group. Assisted vaginal deliveries were $15 \%$ in combined spinal epidural analgesia group compared to $10.3 \%$ in non CSE group which was statistically insignificant. LSCS was $7.5 \%$ in control CSE group compared to $10.3 \%$ in non CSE group. Maternal satisfaction was excellent in majority of parturients in CSE group. The perinatal outcome was not affected in CSE group. The incidence of complications were very minimal in present study.

Conclusions: Authors concluded that combined spinal epidural analgesia provides safe and excellent analgesia with no significant increase in the caesarean section and instrumental delivery rates. In addition, CSE decreases the duration of first stage of labour with no effect on perinatal outcome.

Keywords: Combined spinal epidural analgesia, Fentanyl, Levobupivacaine, Visual analog scale

\section{INTRODUCTION}

Labour is one of the most painful experiences in the life of a woman. "The delivery of the infant into the arms of a conscious and pain-free mother is one of the most exciting and rewarding moments in medicine" Moir. Pain relief in labour has always been surrounded with myths and controversies. Hence, providing effective and safe analgesia during labour has remained an ongoing challenge.

The International Association for the Study of Pain (IASP) declared 2007-2008 as the 'Global Year against Pain in Women-Real Women, Real Pain'. The focus was 
to study both acute pain and chronic pain in women. Labour pain was found to be a good study model for treating acute pain. Increasing knowledge of the physiology and pharmacotherapy of pain and the development of obstetric anaesthesia as a subspecialty has improved the training in obstetric anaesthesia, leading to an overall improvement in the quality of labour pain relief.

The updated guidelines for labour analgesia as proposed by American Society of Anaesthesiologists (ASA) task force and committee on Standards and practice parameters in 2016, recommend that choice of analgesia technique depend on the medical status of patient, anaesthetic risk factors, obstetric risk factors, patient's preferences, progress of labour and resources at facility. ${ }^{1}$ With sufficient resources, neuraxial analgesic techniques should be offered among analgesic options for labour with primary goal of providing adequate analgesia with minimal motor block. ${ }^{1}$

The use of neuraxial techniques such as Epidural and Combined spinal epidural analgesia has been shown to be the most effective modality for pain relief in labour. ${ }^{2}$ In addition to providing analgesic benefit to mother, neuraxial analgesia can be converted to surgical anaesthesia if operative delivery is required..$^{3,4}$

This prospective study was conducted to study the effects of CSE on the duration of labour, mode of delivery, effects on the neonate and any adverse side effects. The primary outcome studied were duration of active phase, duration of second stage of labour, mode of delivery, rate of cervical dilatation, rate of instrumental delivery, rate of emergency caesarean and neonatal condition at birth.

The effectiveness of analgesia was assessed by noting the time for onset of analgesia, duration of action of intrathecal dose of anaesthesia, number of epidural top ups required, interval between onset of analgesia to delivery. In present study authors used visual analog scale to measure pain.

In present country, the awareness is still lacking and, except few centres that run a comprehensive labour analgesia programme, the national awareness or acceptance of pain-relieving options for women in labour virtually does not exist.

\section{METHODS}

The comparative clinical study was conducted to study the effects of combined spinal epidural analgesia on the course of labor, effects on the fetus and neonate also the effectiveness of analgesia. The present study was carried out in labour ward in patients fulfilling the inclusion criteria. Nulliparous parturients who are fulfilling inclusion criteria are divided into 2 groups. CSE group $(n=40)$ women who are given combined spinal epidural analgesia at $3-5 \mathrm{~cm}$ of cervical dilatation. Non CSE group $(n=40)$ women who were not administered any type of analgesia.

\section{Inclusion criteria}

- Nullipara fulfilling the following criteria

- $\quad$ Age group between 18-30 years

- Height above $145 \mathrm{~cm}$

- Single live gestation with term gestation with vertex presentation

- Women with spontaneous onset of labour, in active phase (cervical dilatation $3-5 \mathrm{~cm}$ )

- Women giving informed written consent.

\section{Exclusion criteria}

- Multigravida

- Age less than 18 years or above 30 years

- High risk pregnancy such as severe anemia, preeclampsia, gestational diabetes etc.

- Women with other comorbid conditions such as hypertension, diabetes, cardiac diseases, neurovascular diseases

- Malpresentation, cephalopelvic disproportion

- cervical dilatation more than $5 \mathrm{~cm}$

- Presence of contraindications for epidural analgesia.

The parturients were first examined by obstetrician, a detailed obstetric history was taken and fetal presentation was confirmed by clinical examination. The parturients in active phase of labour (cervical dilatation $3-4 \mathrm{~cm}$, regular uterine contractions) who consented for CSE analgesia were enrolled into CSE group and those declining consent were enrolled into non CSE group. CSE parturients who demanded for labour analgesia were evaluated by the anaesthetist. Informed written consent was taken. An 18G IV cannula was inserted and the patient was started on RL solution. The patient was positioned in sitting position, under aseptic precautions, the skin over the lower thoracic and lumbar region was cleaned and the area draped. The best inter-lumbar space between L3- L4 or L4-L5 was identified and infiltrated with $2 \%$ lignocaine. A pre-packed set containing 18gauge epidural needle, 20-gauge epidural catheter and 27gauge spinal needle was used. The epidural space was identified using the loss of resistance to saline technique, after which the spinal needle was inserted through the epidural needle. Upon visualization of backflow of cerebrospinal fluid, an intrathecal dose of $1.25 \mathrm{mg}$ of levobupivacaine with $25 \mathrm{mcg}$ fentanyl was given. The epidural catheter was then inserted $3-5 \mathrm{~cm}$ into the epidural space and secured. The parturient was then positioned supine with left uterine displacement. The level of sensory blockade was checked to ensure the sensory level was $\geq \mathrm{T} 10$. Efficacy and the side effects of CSE (hypotension, motor block etc) were watched in coordination with the attending anaesthetist. Continuous monitoring of fetal heart sound was done and partograph was used to record the progress of labour. 
Mother's vital parameters were recorded throughout the study, every 5minutes for at least $15 \mathrm{~min}$ after the administration of the drug and then every $15 \mathrm{~min}$ thereafter. Hypotension was planned to be treated with IV fluid administration and vasopressor. Degree of pain relief-analgesia was measured using verbal numerical rating scale. Assessment of motor block was done as per Bromage score.

Analgesia was maintained with low dose intermittent epidural top ups administered on demand. Bolus of $10 \mathrm{ml}$ of $0.0625 \%$ Levobupivacaine with $2 \mathrm{mcg} / \mathrm{ml}$ of fentanyl will be given through the epidural catheter when verbal numerical rating score (VAS)for pain is more than 4 . Duration of action of epidural top ups and number of top ups given were noted. Assessment of progress of labour was done. Cervical dilatation, effacement, station of head, uterine contraction and FHR were noted. Fetal monitoring was done with electronic fetal monitor and auscultation of FHR every $15 \mathrm{~min}$ with fetal Doppler. Obstetric management was similar in both groups. Amniotomy was done if membranes were intact and oxytocin augmentation was started. Pelvic examination was done at regular interval as per labour protocol to assess the progress of labour.

Duration of active phase of first stage of labour and second stage of labour were noted. Mode of deliveryspontaneous vaginal/ assisted vaginal/ caesarean section and the indication for the same was noted. Assisted vaginal delivery/ caesarean section was considered if abnormal FHR tracing, caesarean section is considered for dystocia, if arrest of cervical dilatation in1st stage or arrest of descent in 2nd stage. APGAR score was assessed at $1 \mathrm{~min}$ and $5 \mathrm{~min}$ following delivery. Complications, side effects if any were noted and treated accordingly.

Throughout labour, sensory level, motor block and pain score were assessed at hourly intervals. The degree of motor block was assessed using the Modified Bromage Score (MBS) where 1 means complete block i.e. unable to move feet or knee; 2 means almost complete block i.e. able to move feet only; 3 is partial block i.e. just able to move the knees; 4 means detectable weakness of hip flexion while supine and 5 is no detectable weakness of hip flexion while supine. Parturients with MBS $\leq 2$ and/or sensory level $\geq \mathrm{T} 6$ was regarded as having an excessively dense or high epidural block respectively and managed accordingly. Pain was assessed using Visual Analogue Scale with scores ranging from 0 , indicating no pain to 10 , being the worst pain imaginable. Breakthrough pain was managed by administering additional epidural bolus doses.

\section{RESULTS}

Present study included 80 nulliparous women. They were divided into two groups, CSE group $(n=40)$ women who were given combined spinal epidural analgesia at 3-4 cm of cervical dilatation and non CSE group $(n=40)$ women who were not given any form of analgesia throughout the labour. The outcomes measured were hemodynamics of the patient, pain score, bolus requirement, mode of delivery, duration of labour, neonatal outcome and complications if any.

Table 1: Demographic profile and vital parameters.

\begin{tabular}{|c|c|c|c|c|c|c|}
\hline \multirow{2}{*}{ Variables } & \multicolumn{2}{|c|}{$\mathrm{CSE}^{\mathrm{a}}$ group $(\mathrm{n}=40)$} & \multicolumn{2}{|c|}{ Non-CSE group $(n=39)$} & \multirow{2}{*}{ t-value } & \multirow{2}{*}{ p-value } \\
\hline & Mean & SD & Mean & SD & & \\
\hline Age (in years) & 22.23 & 2.1 & 22.36 & 1.9 & 0.29 & 0.71 \\
\hline Height (in $\mathrm{cm}$ ) & 155.43 & 2.8 & 154.9 & 2.7 & 0.83 & 0.70 \\
\hline Weight (in kg) & 56.48 & 3.3 & 56.10 & 4.1 & 0.44 & 0.25 \\
\hline $\operatorname{BMI}\left(\mathrm{kg} / \mathrm{m}^{2}\right)$ & 23.37 & 1.16 & 23.38 & 1.56 & 0.02 & 0.97 \\
\hline Pulse rate (per minute) & 83.20 & 3.9 & 83.23 & 3.4 & 0.03 & 0.28 \\
\hline
\end{tabular}

Independent t-test used; ${ }^{\mathrm{a}}$-combined spinal epidural analgesia; $\mathrm{p}$-value $<0.05$ is significant.

Majority of the patients were between the age group was 18-25 years. Mean age was 22.23 in group A and 22.36 in group B. Mean height in group A was 155.43 and in group B was 154.9.

The $\mathrm{p}$ value was $<0.05$ which was statistically insignificant. The mean weight in group A was $56.48 \mathrm{~kg}$ and $56.1 \mathrm{~kg}$ in group B. Mean BMI was comparable in both groups and $\mathrm{p}$ value was statistically insignificant.
The hemodynamics of the parturients were monitored continuously starting at baseline (before CSE), $5 \mathrm{~min}, 10$ min, 15 min, $30 \mathrm{~min}, 45 \mathrm{~min}, 1,1.5,2,3$, 4, 5, 6 hours. Parturients monitored in both groups till they deliver. In present study none of the parturient had hypotension as side effect in CSE group.

The mean pulse rate was $83.2 \pm 3.9$ in CSE group as compared to $83.23 \pm 3.4$ in non CSE group. 


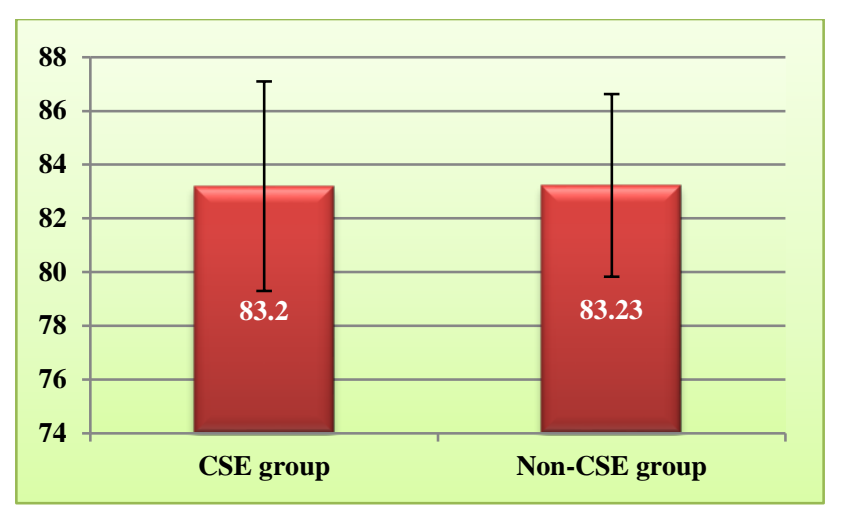

Figure 1: Mean distribution of mother's pulse rate.

The mean systolic BP was $123.85 \mathrm{mmHg}$ in CSE group and it was $124.21 \mathrm{mmHg}$ in non CSE group.

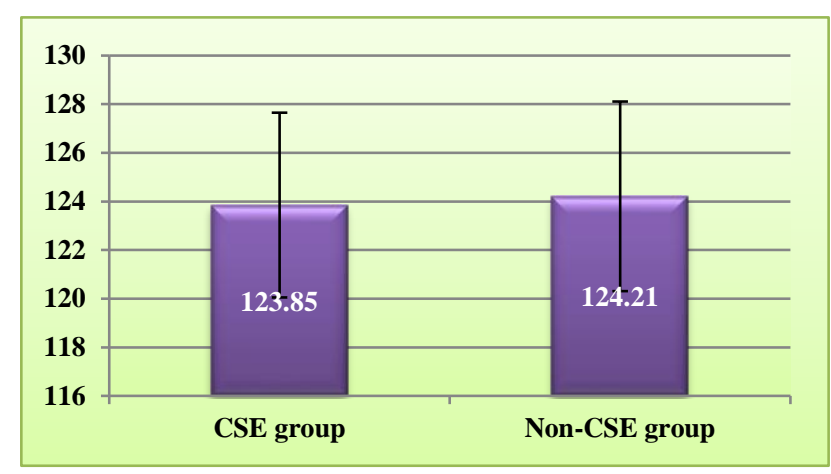

Figure 2: Mean systolic BP among parturients.

The mean diastolic BP was $82.85 \mathrm{mmHg}$ in CSE group and $80.97 \mathrm{mmHg}$ in non CSE group.

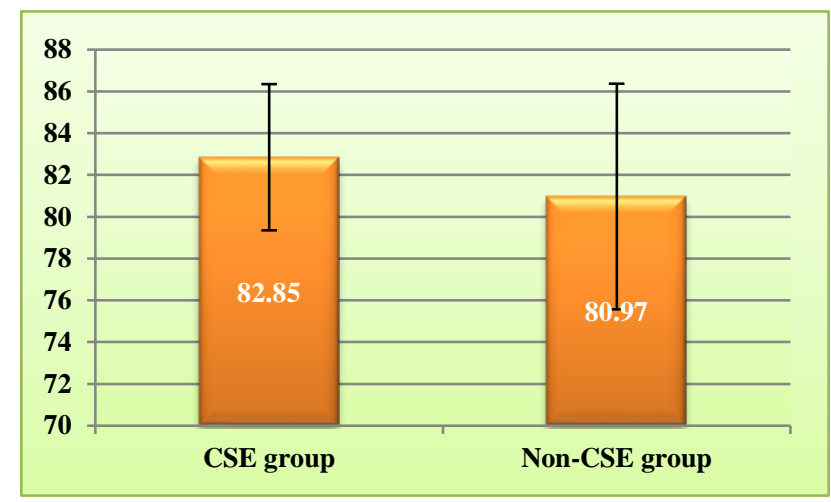

Figure 3: Mean diastolic BP among parturients.

The mean initial cervical dilatation was $3.76 \mathrm{~cm}$ in CSE group and $3.67 \mathrm{~cm}$ in non CSE group at the time of inclusion for study. The duration of active phase of labour in CSE group was $139 \pm 41.2 \mathrm{~min}$ as compared to $251.1 \pm 57.9 \mathrm{~min}$ in non CSE group. Mean duration of active phase of labour was shorter in CSE group as compared to non CSE group which was statistically significant. Among the parturients delivered vaginally/ underwent caesarean section or instrumental delivery at the second stage, the shortest duration of active phase was1hr 30min in CSE group as compared to 2-hour 30 min in non CSE group. The longest duration was up to 4 hours in CSE group and 6hr in non CSE group.

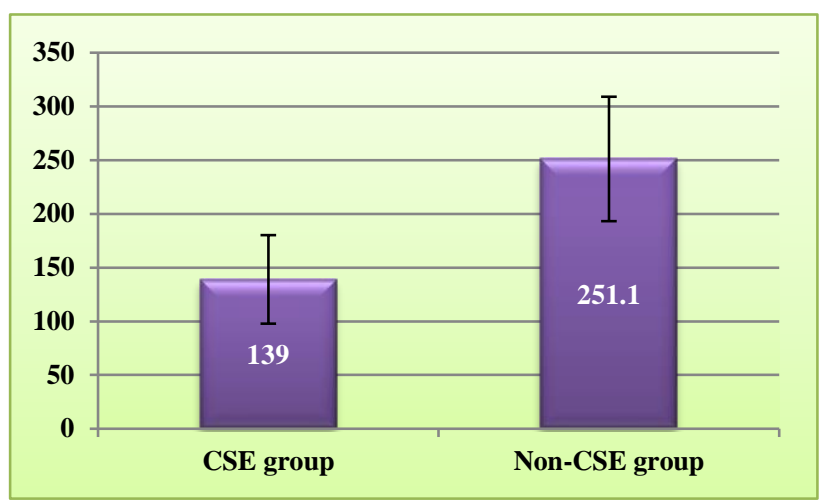

Figure 4: Comparison of duration of active phase of labour (in minutes).

The rate of cervical dilatation was $2.63 \pm 0.66 \mathrm{~cm} / \mathrm{hr}$ in CSE group and $1.45 \pm 0.38 \mathrm{~cm} / \mathrm{hr}$ in non CSE group. The difference was statistically significant.

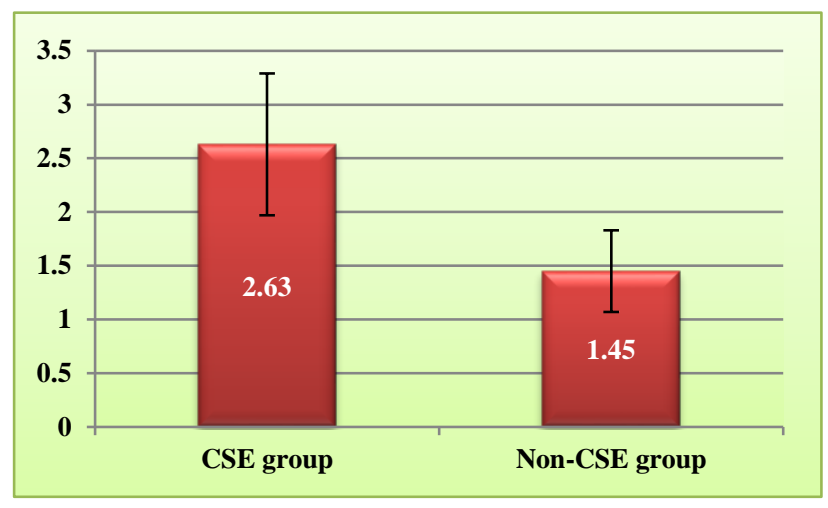

Figure 5: Comparison of rate of cervical dilatation (in $\mathrm{cm} / \mathrm{hr}$ ).

The mean duration of second stage of labour was 47.1 $\pm 19.4 \mathrm{~min}$ in CSE group and it was $42.3 \pm 15.2 \mathrm{~min}$ in non CSE group which is not statistically significant.

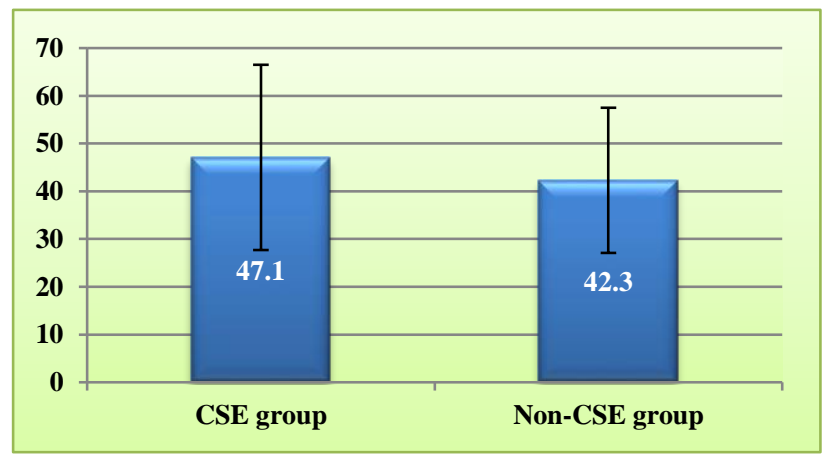

Figure 6: Duration of second stage of labour (in minutes). 
The mean VAS score in CSE group was 1 as compared to 7 in non CSE group. Excellent pain relief was observed in CSE group which is statistically significant.

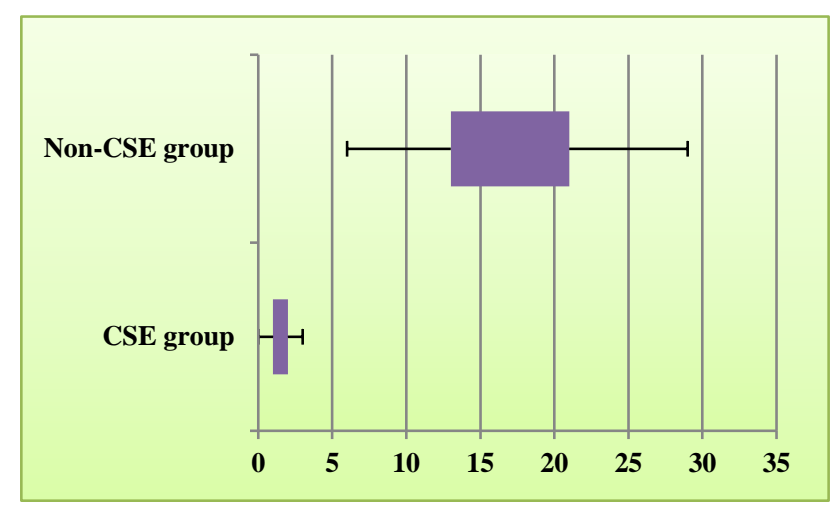

Figure 7: Comparison of intensity of labour pain using Visual Analogue Scale (VAS) among the parturients.

Majority of the parturients in both the groups delivered vaginally without any instrumentation, $77.5 \%$ in CSE group and $79.5 \%$ in non CSE group.

Increased number of instrumental deliveries were observed in CSE group (15\%) as compared to non CSE group $(10.3 \%)$. However, it is not statistically significant.

There is no much difference in the rate of caesarean delivery, in CSE group it was $7.5 \%$ and $10.3 \%$ in non CSE group which is not statistically significant.

In CSE group 2 parturients underwent LSCS in view of non-progress of labour and 1 parturient underwent LSCS in view of fetal distress.

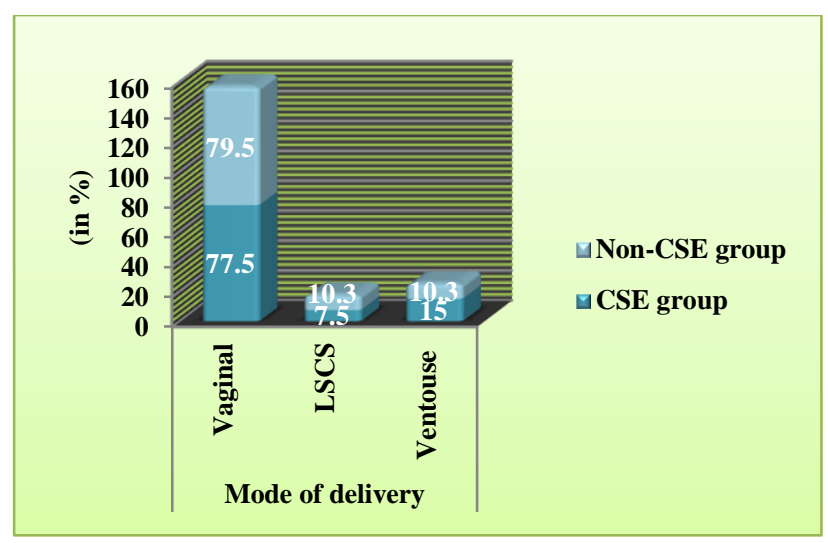

Figure 8: Relationship between modes of delivery between the groups.

There is no significant variability of FHR changes among the two groups.

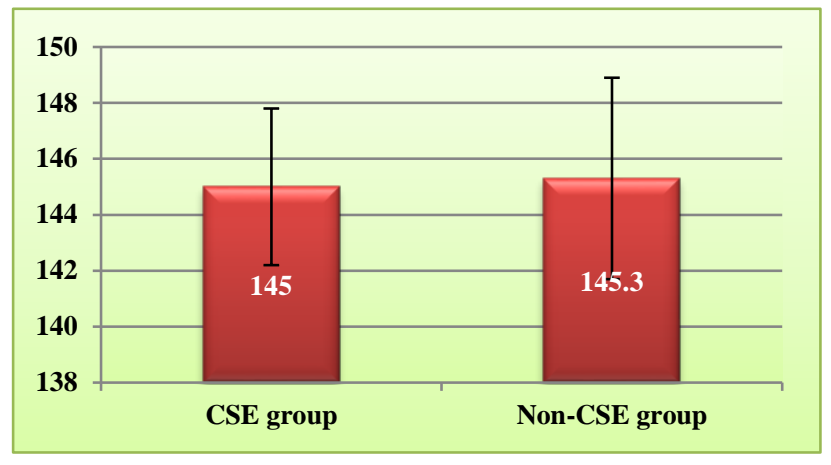

Figure 9: Comparison of mean fetal heart rate between the groups (in beats/min).

All the neonates had good APGAR score at birth.

Table 2: Comparison of APGAR score of neonates among two groups.

\begin{tabular}{|c|c|c|c|c|c|c|}
\hline & \multirow{2}{*}{ Variables } & \multicolumn{2}{|c|}{ CSE group $(n=40)$} & \multicolumn{2}{|c|}{ Non-CSE group $(\mathrm{n}=39)$} & \multirow{2}{*}{ p-value } \\
\hline & & Mean & SD & Mean & SD & \\
\hline \multirow[t]{2}{*}{ Pre-delivery ${ }^{\mathbf{a}}$} & Fetal Heart Rate (in beats/min) & 145.0 & 2.8 & 145.3 & 3.6 & 0.13 \\
\hline & & Median & IQ range & Median & IQ range & p-value \\
\hline \multirow{2}{*}{ Post-delivery $^{b}$} & APGAR $1^{\text {st }}$ minute & 9 & 9,9 & 9 & 9,9 & 0.09 \\
\hline & APGAR $5^{\text {th }}$ minute & 9 & 9,9 & 9 & 9,9 & 0.16 \\
\hline
\end{tabular}

a-Independent t-test used; ${ }^{\text {- }}$-Mann Whitney $\mathrm{U}$ test used; $\mathrm{p}$-value $<0.05$ is significant.

Effectiveness of analgesia: The time taken for onset of analgesia was assessed by noting the time taken for VAS score to become less than 4 . In present study mean time taken for the onset of analgesia following intrathecal dose was $252.5 \pm 65.8$ seconds.

The analgesia following intrathecal dose lasted for $74.5 \pm 15.6 \mathrm{~min}$. The parturient was given epidural top up once VAS score was more than 4 . The mean duration of action of epidural top up dose was $66 \pm 8.8$ min. Mean number of top ups required until delivery were 1.5 \pm 0.6 .2$ parturients delivered with nil top ups.

Majority of the parturients required 2 top ups until delivery. The mean interval between analgesia and delivery was $187 \pm 42.9 \mathrm{~min}$. 


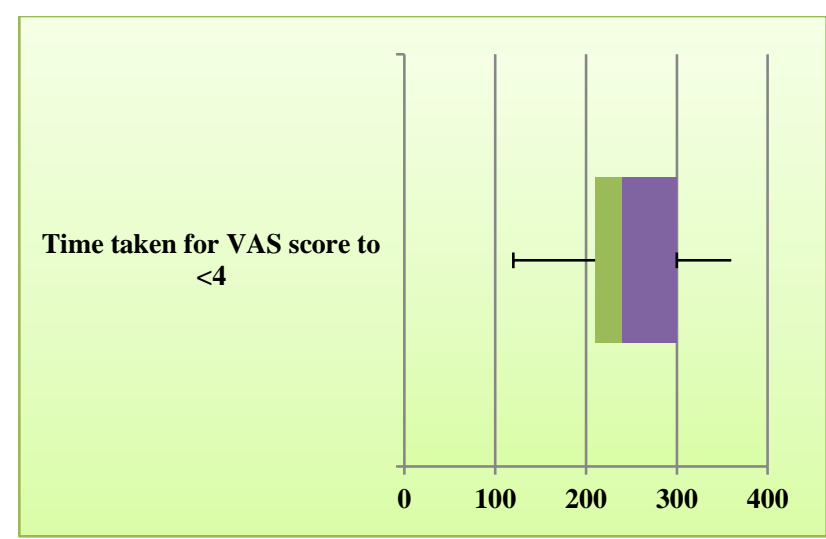

Figure 10: Time for onset of analgesia (in seconds).

Maternal side effects observed: 12 patients in the CSE group had pruritus immediately after the intrathecal dose of anaesthetic which subsided after symptomatic treatment. One patient had vomiting. None of the parturients had hypotension or motor blockade in present study.

Comparison of satisfactory level between the two groups: The maternal satisfaction was assessed in both groups postnatally. Majority of the parturients in the CSE group had excellent satisfaction compared to non CSE group. More number of parturients $18 \%$ had poor satisfaction and $25.6 \%$ had average satisfaction in non CSE group.

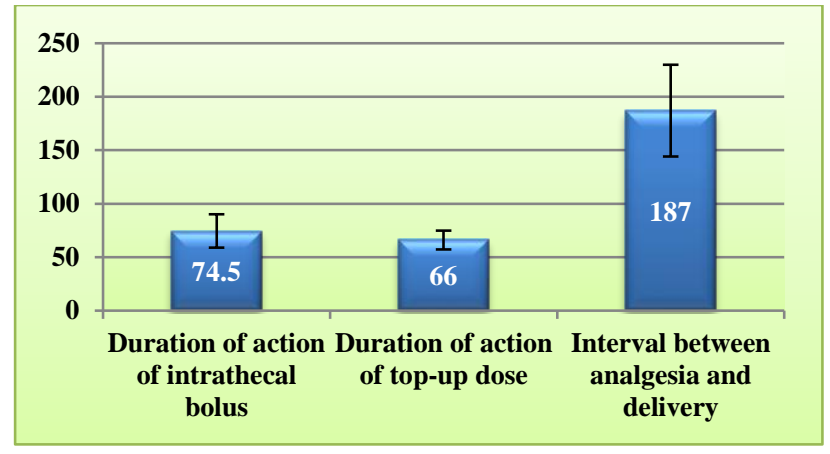

Figure 11: Duration of action of intrathecal and epidural top up dose (in minutes).

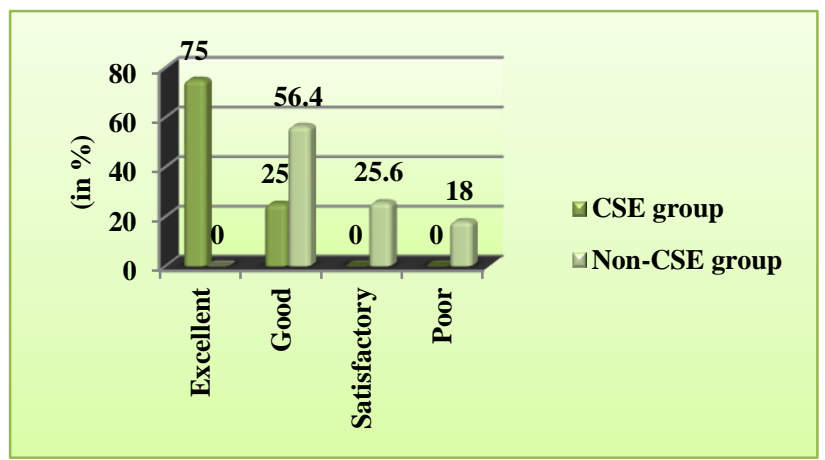

Figure 12: Comparison of maternal satisfaction between the groups.

Table 3: Effect of CSE on delivery and outcome.

\begin{tabular}{|c|c|c|c|c|c|c|}
\hline \multirow{2}{*}{ Variables } & \multicolumn{2}{|c|}{ CSE group (n=40) } & \multicolumn{2}{|c|}{ Non-CSE group $(n=39)$} & \multirow{2}{*}{$\chi^{2}$} & \multirow{2}{*}{ p-value } \\
\hline & No. & $\%$ & No. & $\%$ & & \\
\hline \multicolumn{7}{|l|}{ Mode of Delivery ${ }^{a}$} \\
\hline Vaginal & 31 & 77.5 & 31 & 79.5 & \multirow{3}{*}{0.53} & \multirow{3}{*}{0.76} \\
\hline LSCS & 3 & 7.5 & 4 & 10.3 & & \\
\hline Ventouse & 6 & 15.0 & 4 & 10.3 & & \\
\hline \multicolumn{7}{|l|}{ Side effects (pruritis, vomiting) ${ }^{a}$} \\
\hline Present & 13 & 32.5 & 0 & 0.0 & \multirow{2}{*}{15.1} & \multirow{2}{*}{$<0.001$} \\
\hline Absent & 27 & 67.5 & 39 & 100.0 & & \\
\hline \multicolumn{7}{|l|}{ Maternal satisfaction ${ }^{b}$} \\
\hline Excellent & 30 & 75.0 & 0 & 0.0 & \multirow{4}{*}{60.6} & \multirow{4}{*}{$<0.001$} \\
\hline Good & 10 & 25.0 & 22 & 56.4 & & \\
\hline Satisfactory & 0 & 0.0 & 10 & 25.6 & & \\
\hline Poor & 0 & 0.0 & 7 & 18.0 & & \\
\hline \multirow{2}{*}{ Variables } & \multicolumn{2}{|c|}{ CSE group } & \multicolumn{2}{|c|}{ Non-CSE group } & \multirow{2}{*}{ t-value ${ }^{c}$} & \multirow{2}{*}{ p-value } \\
\hline & Mean & SD & Mean & SD & & \\
\hline Duration of active labour (minutes) & 139.0 & 41.2 & 251.1 & 57.9 & 9.8 & 0.015 \\
\hline Duration of $2^{\text {nd }}$ stage labour (minutes) & 47.1 & 19.4 & 42.3 & 15.2 & 1.19 & 0.08 \\
\hline Cervical dilatation rate ( $\mathrm{cm}$ per hour) & 2.63 & 0.66 & 1.45 & 0.38 & 9.29 & 0.009 \\
\hline \multirow{2}{*}{ Variables } & CSE gro & & Non-CS & group & \multirow{2}{*}{ u-value } & \multirow{2}{*}{ p-value } \\
\hline & Median & IQ range & Median & IQ range & & \\
\hline Visual Analogue Scale ${ }^{\mathbf{d}}$ & 1 & 0,1 & 7 & 6,8 & 16.1 & $<0.001$ \\
\hline
\end{tabular}

a indicates Pearson Chi-square test used; b indicates Fisher's exact test used; $\mathrm{c}$ indicates Independent $\mathrm{t}$-test used; $\mathrm{d}$ indicates Mann Whitney $\mathrm{U}$ test used; p-value $<0.05$ is significant. 


\section{DISCUSSION}

As noted by ASA and ACOG, 'there is no other circumstance where it is considered acceptable for a person to experience severe pain amenable to safe intervention while under a physician's care. ${ }^{5}$ Unfortunately, labour represents one of few circumstances in which provision of effective analgesia is alleged to interfere with parturients and obstetricians' goal. Neuraxial block technique is currently the gold standard for labour analgesia. In present study authors have evaluated the effects of combined spinal epidural analgesia on the course of labour and feto-maternal outcome in relation to parturients not receiving any analgesia. Authors have also assessed the effectiveness of combined spinal epidural analgesia. Levobupivacaine $1.25 \mathrm{mg}$ with $25 \mathrm{mcg}$ fentanyl was given intrathecally followed by bolus of $10 \mathrm{ml}$ of $0.0625 \%$ Levobupivacaine with $2 \mathrm{mcg} / \mathrm{ml}$ of fentanyl given through the epidural catheter when VAS score is more than 4 . The parturients were comparable in regard to age, parity, weight and cervical dilatation in both groups.

In present study mean initial cervical dilation when CSE was administered to the patients was $3.76 \mathrm{~cm} \pm 0.29 \mathrm{~cm}$. In 2004, ACOG had published epidural analgesia may be delayed until a cervical dilation of $4-5 \mathrm{~cm}$ is reached. However, Wong et al, in an RCT of 750 nulliparous parturients concluded that there was no difference in operative delivery or caesarean rates when neuraxial analgesia was administered early in labour $(2 \mathrm{~cm})$ when compared with the group where epidural analgesia was administered late in labour $(4-5 \mathrm{~cm})$ and revised the statement as 'maternal request is a sufficient indication for pain relief'. 6,7

Indeed, given the complicated neurohumoral and mechanical processes involved in childbirth it would be unreasonable to expect that neuroblockade of lower half of the body would not have an effect on this process. However maternal, fetal factors and obstetric management-not the analgesia are the most important determinants of outcome of labour. ${ }^{8,9}$ New evidence suggests that genetic polymorphism in oxytocin receptor, Catecholamine- O-Methyl transferase, beta 2 adrenergic receptor, ADR B2genes affect the progress of labour. ${ }^{8,9}$ Whether these genotypes interact with neuraxial analgesia to affect the progress of labour requires further study with large number of parturients

The rate of cervical dilatation was $2.63 \pm 0.66 \mathrm{~cm} /$ hour in CSE group as compared to $1.45 \pm 0.38 \mathrm{~cm} /$ hour in Non CSE group which was statistically significant. In a RCT, Tsen et al, observed a higher rate of cervical dilatation in women who received CSE analgesia than in those who received only epidural analgesia. ${ }^{10}$ The duration of first stage of labour will be determined by the intensity of uterine contraction, the rate of dilatation of cervix and the descent of the presenting part. A RCT by Morgan-Oritz et al, showed decrease in the duration of first stage of labour in parturients who received labour analgesia. ${ }^{11}$ Another study by Agarwal D et al showed the shorter mean duration of labour in epidural group compared to control group. ${ }^{12}$ In present study the mean duration of active phase of labour in CSE group was $139 \pm 41.2 \mathrm{~min}$ and that in the control group was $251.1 \pm 57.9 \mathrm{~min}$. It is well documented that there is a correlation between endogenous plasma epinephrine and cortisol levels with labour progression. ${ }^{13}$ The decrease in alpha and beta receptor stimulation following intrathecal analgesia may enhance uterine perfusion leading to a more effectual contraction pattern. ${ }^{14,15}$

The duration of second stage of labour was $47.1 \pm 19.4$ min in CSE group as compared to $42.3 \pm 15.2$ min in non CSE group. The difference was statistically insignificant. Though epidural analgesia has been claimed to be associated with prolonged second stage because of concomitant weakness of pelvic floor muscles that reduces effective maternal pushing, this is not the case nowadays with the use of very low concentration of anesthetic agents combined with opioids. This is confirmed by a recently published meta-analysis on the effect of low concentration versus high concentration local anesthetics for labour analgesia on obstetric and anesthetic outcome. ${ }^{16}$

The rate of instrumental delivery and caesarean section were similar in both the groups. CSE provides faster, excellent and safe analgesia with no significant increase in the caesarean section and instrumental delivery rates. In present study fetal heart rate during labour analgesia was within normal limits. There was no incidence of post epidural bradycardia. There was no significant difference between NICU admissions in both the groups. The most common side effect with CSE analgesia was pruritus seen in $32.5 \%$ of parturients. However, it was transient and subsided with symptomatic treatment. The mean pain score was 1 in CSE group as compared to 7 in non CSE group. Excellent pain relief was observed in CSE group. A recent study comparing it with traditional epidural analgesia also showed that although both techniques were excellent analgesic options, CSE provided significantly faster and better pain relief during first stage of labour. ${ }^{17}$ In addition CSE decreases the duration of first stage of labour with no effect on perinatal outcome.

In present country, the awareness is still lacking and, except few centers that run a comprehensive labour analgesia programme, the national awareness or acceptance of pain-relieving options for women in labour virtually does not exist.

\section{CONCLUSION}

Authors concluded that combined spinal epidural analgesia with $1.25 \mathrm{mg}$ of levobupivacaine with $25 \mathrm{mcg}$ fentanyl given intrathecally and bolus of $10 \mathrm{ml}$ of $0.0625 \%$ Levobupivacaine with $2 \mathrm{mcg} / \mathrm{ml}$ of fentanyl given through the epidural catheter when VAS score is 
more than 4 provides safe and excellent analgesia with no significant increase in the caesarean section and instrumental delivery rates. In addition, CSE decreases the duration of first stage of labour with no effect on perinatal outcome.

\section{ACKNOWLEDGMENTS}

Authors would like to thank Dr Ramalingappa C. Antaratani, Professor and Head, Department OBG, KIMS, Hubli for his encouragement and Dr Safiya I. Shaik Professor and Head, Department of Anesthesiology, KIMS, Hubli for her support; special thanks to all staff and post graduates of $\mathrm{OBG}$ and Anesthesia department for their immense support.

Funding: No funding sources

Conflict of interest: None declared

Ethical approval: The study was approved by the Institutional Ethics Committee

\section{REFERENCES}

1. Practice guidelines for Obstetric Anaesthesia, An updated report by the American Society of Anaesthesiologists Task force on the Society of Obstetric Anaesthesia and perinatology, Anaesthesiology. 2016:124(2);270-300.

2. Capogna G, Camorcia M, Stirparo S, Farcomeni A. Programmed intermittent epidural bolus versus continuous epidural infusion for labor analgesia: the effects on maternal motor function and labor outcome. A randomized double-blind study in nulliparous women. Anesthes Analges. 2011;113(4):826-31.

3. Braveman FR, Scavana BM, Wong CA, et al. Obstetric Anaesthesia. In: Barash PG, Cullen BF, Stoelting RK, et al, eds. Clinical Anaesthesia. $6^{\text {th }}$ ed. Philadelphia Lipincott, William and Wilkins; 2009;1137-1170.

4. Afolabi BB, Leu F. Regional versus General Anesthesia for C-section; Cochrane data base system, Rev. 2012(10),CD0043508.

5. ACOG Committee Opinion No. 295. American College of Obstetricians and Gynecologists. Pain relief during labour. Obstet Gynecol. 2004;104:213.

6. Wong CA, Scavone BM, Peaceman AM, McCarthy RJ, Sullivan JT, Diaz NT, et al. The risk of cesarean delivery with neuraxial analgesia given early versus late in labor. New England J Med. 2005;352(7):65565.

7. American College of Obstetricians and Gynecologists Committee on Obstetric Practice. ACOG Committee opinion No.339; analgesia and caesarean delivery rates. Obstet Gynecol. 2006;107:1487-8.

8. Reitman E, Conell-Price J, Evansmith J, Olson L, Drosinos S, Jasper N, et al. $\beta 2$-adrenergic receptor genotype and other variables that contribute to labor pain and progress. Anesthesiology: J Am Soc Anesthesiol. 2011;114(4):927-39.

9. Terkawi AS, Jackson WM, Thiet MP, Hansoti S, Tabassum R, Flood P. Oxytocin and catechol-Omethyltransferase receptor genotype predict the length of the first stage of labor. Am J Obstet Gynecol. 2012;207(3):184-e1.

10. Tsen LC, Thue B, Datta S, Segal S. Is combined spinal-epidural analgesia associated with more rapid cervical dilation in nulliparous patients when compared with conventional epidural analgesia?. Anesthesiology: J Am Soc Anesthesiol. 1999;91(4):920.

11. Morgan-Ortiz F, Quintero-Ledezma JC, Perez-Sotelo JA, Trapero-Morales M. Evolution and quality of care during labor and delivery in primiparous patients who underwent early obstetrical analgesia. Gynecol Obstet Mexico. 1999;67:522-6.

12. Agrawal D, Makhija B, Arora M, Haritwal A, Gurha P. The effect of epidural analgesia on labour, mode of delivery and neonatal outcome in nullipara of India, 2011-2014. J Clin Diagnos Res: JCDR. 2014;8(10):OC03.

13. Lederman RP, Lederman E, Work BA, Mc Cann DS. The relationship of maternal anxiety, plasma catechol amines and plasma cortisol to progress in labour. Am J Obstet Gynecol. 1978;132(5):495-500.

14. Anim-Soumuah M, Smyth R, Jones L. Epidural versus non-epidural in labour (Review). The Cochrane Database of Systematic Reviews. 2011;12:CD000331.

15. Jouppila R, Hollmen A. The effect of segmental epidural analgesia on maternal and fetal acid base balance, lactate, serum potassium and creatinine phosphokinase during labour. Acta Anaesthesiologica Scandinavia. 1976;20(3):259-268.

16. Sultan P, Murphy C, Halpern S, Carvalho B. The effect of low concentrations versus high concentrations of local anesthetics for labour analgesia on obstetric and anesthetic outcomes: a meta-analysis. Canadian J Anes. 2013;60(9):840-54.

17. Gambling D, Berkowitz J, Farrell TR, Pue A, Shay D. A randomized controlled comparison of epidural analgesia and combined spinal-epidural analgesia in a private practice setting: pain scores during first and second stages of labor and at delivery. Anesthes Analges. 2013;116(3):636-43.

Cite this article as: Bembalgi S, Kallapur B, Prasad S, Shruthi M, Amble AS. Study of effects of combined spinal epidural analgesia on the course of labour and feto maternal outcome in comparison with the parturients receiving no analgesia. Int J Reprod Contracept Obstet Gynecol 2018;7:3990-7. 